\title{
Makna BookTube bagi Para Pembaca Buku di Era Digital
}

\author{
Andalusia Neneng Permatasari ${ }^{\mathrm{a}, 1}$, Izni Nur Indrawati Maulani ${ }^{\mathrm{b}, 2}$, Kelik Nursetiyo Widiyanto ${ }^{\mathrm{c}, 3}$, dan \\ Kiki Zakiah Darmawan ${ }^{\mathrm{d}, 4 *}$ \\ a,b,c,d Universitas Islam Bandung \\ Email: ${ }^{1}$ andalusia@unisba.ac.id, ${ }^{2}$ izni.indrawati@gmail.com, dan ${ }^{3}$ kiki.zakiah@unisba.ac.id* \\ *corresponding author
}

Keywords:

social construction, BookTube, new media

\section{Kata Kunci:}

konstruksi sosial, BookTube, media baru

\begin{abstract}
The rapid development of information communication technology has led to the full utilization of digital. Online media are replacing conventional print media, digital books are starting to be looked at by publishers, and book reviews usually in regular media were transformed into the form of audiovisual called BookTube. This study aims to find out, understand, and explain how book readers and viewers of BookTube shows interpret the meaning of BookTube. The method used is a qualitative research method with a phenomenological approach. The results of this study are the construction of meaning built for the BookTube. First, BookTube is a complement to written reviews because they still feel the BookTube cannot present the essence of a book reviewer. Second, BookTube as a substitute for written book reviews because changes occur so fast, like it or not, BookTube can be used as a substitute for a new form of a book review.
\end{abstract}

\begin{abstract}
ABSTRAK
Perkembangan teknologi komunikasi informasi yang begitu cepat menyebabkan pemanfaatan penuh pada digital. Media-media online menggantikan media cetak konvensional, buku-buku digital mulai dilirik penerbit, sampai resensi buku yang biasanya ada di rubrik media cetak kini bertransformasi dalam bentuk audio visual. Perubahan resensi buku tersebut disebut BookTube. Penelitian ini bertujuan untuk mengetahui, memahami, dan menjelaskan bagaimana para pembaca buku dan penonton tayangan BookTube memaknai kehadiran BookTube. Metode yang digunakan adalah metode penelitian kualitatif dengan pendekatan fenomenologi. Hasil dari penelitian ini adalah adanya konstruksi makna yang dibangun pada BookTube. Pertama, BookTube sebagai pelengkap resensi tertulis karena masih merasa BookTube tidak dapat menghadirkan esensi dari sebuah resensi. Kedua, BookTube sebagai pengganti resensi tertulis karena perubahan yang terjadi begitu cepat, mau tidak mau, BookTube dapat dijadikan pengganti bentuk resensi yang baru.
\end{abstract}

Copyright (C) 2020 Channel Jurnal Komunikasi. All right reserved.

\section{PENDAHULUAN}

Pada tanggal 15 Maret 2020, Pikiran Rakyat Minggu harus mengucapkan selamat tinggal pada para pembaca setianya. Setelah 54 tahun terbit secara rutin di hari Minggu, Pikiran Rakyat Minggu mengakhiri edisinya di tanggal tersebut. Sebagaimana sudah diketahui, kini masyarakat lebih memilih mencari informasi di internet, dalam hal ini adalah media daring atau online. Berdasarkan hasil survei Badan Pusat Statistik, pada tahun 2017, pembaca media daring meningkat 35,8\% dibanding tahun 2015. Nielsen Indonesia juga mengemukakan jumlah pembaca media cetak semakin merosot. Tentu saja, ini akan sangat berdampak pada media cetak, termasuk penurunan oplah atau berhenti terbit.

Pikiran Rakyat Minggu pada masa kejayannya selalu ditunggu pembaca karena konten sastra, budaya, dan hiburannya dianggap dapat menghibur para pembaca. Inovasi pun dilakukan dengan berbagai program agar sesuai konteks zaman. Pada tahun 2012, redaksi Pikiran Rakyat Minggu merancang rubrik-rubriknya agar dapat menjadi event. Ada rubrik Back to Bosech, Backpaker, Freshion, Foodaholic, PR Kecil, dan lain-lain. Rubrik-rubrik yang dimiliki itu 
ditargetkan menjadi pengikat komunitas sehingga tim marketing merancang event berbasis rubrik (Kartawijaya, 2020). Segala kemungkinan dilakukan agar dapat berkembang dan memenuhi selera pembaca di zaman sekarang.

Tidak hanya Pikiran Rakyat Minggu, sebelumnya sudah lama Koran Tempo Minggu berhenti terbit, tepatnya 11 Oktober 2015. Begitu pula beberapa media cetak yang lebih dahulu berhenti terbit seiring penggunaan internet yang semakin pesat, yaitu Sinar Harapan, Harian Bola, majalah Hai, kawanku, atau Rolling Stone. Beberapa tabloid pun mengalami nasib serupa, seperti tabloid Cek \& Ricek yang berhenti terbit 23 April 2019 (Romelteamedia, 2019). Fenomena yang dialami media-media cetak tersebut adalah dampak dari hadirnya internet dan layanan internet yang dapat dengan mudah dinikmati di layar ponsel. Internet menyediakan informasi dan konten yang dapat dinikmati gratis oleh konsumen. Berdasarkan survei GlobalWebIndex pada tahun 2014-2018, media cetak seperti koran dan majalah hanya dibaca 43 menit per hari. Lain halnya dengan media daring yang dikonsumsi sampai 6 jam 45 menit (Duarte, 2019). Penurunan minat konsumen membaca media cetak berakibat pada sirkulasi media cetak. Di Amerika Serikat, tahun 1994 sirkulasi media cetak dapat mencapai 60 juta, tetapi di tahun 2018 hanya mencapai 35 juta. Pada tahun 1900-an, di Amerika Serikat ada lebih dari 6.000 perusahaan koran. Kini jumlahnya hanya sekitar 4.000 berdasarkan Biro Sensus (Nailufar, 2019). Di Amerika Serikat pun, pada 13 September 2019, Express Post milik CEO Amazon berhenti terbit.

Dengan hilangnya beberapa koran Minggu, ada rubrik yang biasa hadir pun hilang, salah satunya adalah rubrik ulasan atau resensi buku. Ketika blog sedang menjadi sesuatu yang digemari, resensi buku yang biasa ditemui di media cetak seperti koran Minggu, dapat ditemui ditulis di blog oleh para blogger. Walaupun secara kualitas masih jauh dari resensi yang biasa ditulis di media massa, resensi yang ditulis di blog sering menjadi acuan dan dicari ketika hendak mencari kualitas suatu buku. Beberapa komunitas pembaca buku aktif menuliskan resensi atau sekadar komentar tentang sebuah buku di blog. Oleh sebab itu, para blogger yang aktif menulis resensi dan ulasan buku di blog tergabung di komunitas BBI yang merupakan singkatan dari Books Blogger Indonesia.

Seiring perkembangan teknologi informasi dan komunikasi, muncullah YouTube ke permukaan sebagai hal yang trendi di kalangan anak muda. Tidak hanya vlog, para content creator berusaha menyajikan aneka kreativitas yang ditampilkan di YouTube. Salah satunya adalah resensi dan ulasan buku. Jadi, jika biasa membaca rubrik resensi di koran Minggu, kini resensi bisa didengar dan ditonton langsung di YouTube channel content creator spesialis konten buku. Pemilik akun YouTube yang membuat channel hanya untuk membahas serba serbi buku, mulai dari ulasan singkat, resensi, diskusi buku, dan lain-lain disebut BookTuber. Channel YouTube yang menyajikan segala hal terkait buku disebut BookTube.

BookTube adalah nama tidak resmi yang diberikan kepada kumpulan saluran YouTube yang membahas segala hal seputar buku. BookTube adalah akronim yang merupakan gabungan dari book yang bermakna 'buku' dan tube yang mengambil dari kata YouTube. Ariel Bisset, seorang BookTuber (sebutan bagi pemilik akun BookTube) mengatakan bahwa BookTube menjadi sarana berbagi hal para pembaca dan penggemar buku kepada orang-orang yang memiliki passion terhadap buku yang sama. Pengunjung channel BookTube pastilah orang yang memiliki minat dan kegemaran yang sama terhadap buku (Dogget, 2019). Ariel Bisset sendiri telah memiliki 150.000 subscribers (pengikut di YouTube). Saluran BookTube yang dia kelola telah memiliki beberapa segmen tayangan, seperti bookmarked dan booksplosion yang mendiskusikan reading habit atau kebiasaan membaca para pembaca buku. Tidak hanya itu, segmen resensi dan penulis favorit pun rutin ditayangkan.

Mulai bergugurannya koran Minggu yang disinyalir karena minat rendah untuk membaca koran dibanding mengakses internet menciptakan sebuah transformasi dari produk yang bernama "resensi buku" dan kegiatan "meresensi". Di koran rubrik resensi maksimal menghabiskan setengah halaman. Tulisan resensi yang muncul di koran tentu telah melalui proses seleksi ketat dari redaksi. Kini tidak perlu menunggu koran Minggu atau rubrik resensi buku di media cetak, YouTube menghadirkannya dengan cepat dan beragam melalui para BookTuber.

Ada beberapa akun BookTuber internasional yang cukup aktif dan kreatif dalam menyajikan konten BookTube. Sebagai contoh adalah A Clockword Reader dengan 272.000 subscribers, Abookutopia 364.000 subscribers, Readwithcindy 116.000 subscribers, The Book Leo dengan 18.900 subscribers, Spinters Library dengan 4.500 subscribers, Polandbananabook dengan 408.000 subscribers, Squibblereads dengan 26.100 subscribers, dan masih banyak lagi BookTuber lainnya. Berdasarkan pengamatan penulis, sebagian besar BookTuber internasional membahas buku-buku fantasi, seperti Harry Potter, Lord of The Rings, Twilight, Evergen, dan lain-lain. Buku-buku fantasi seperti Harry Potter, Lord of The Rings, Twilight, dan Evergen telah memiliki fans fanatiknya sendiri. Wajar saja jika para BookTuber internasional berlomba menyajikan sajian resensi dan hal lain tentang buku dengan genre fantasi. Segmen penontonnya sudah terlihat secara konkret.

Sajian BookTube yang banyak juga selain genre fantasi adalah tayangan BookTube mengenai buku-buku sastra klasik, seperti karya Jane Austen, Brönte Sisters, Lucy Mt Mongomery, dan lain-lain. Sastra klasik juga cukup banyak diminati pencipta atau pembuat konten BookTube. Sastra klasik dapat meraih audiens yang lebih luas karena karya-karya sastra klasik tidak dimakan zaman. Setiap tahunnya, akan ada orang yang mencari buku-buku sastra klasik. Hal ini juga lah yang menjadi alasan ulasan sastra klasik dihadirkan di BookTube. Target audiensnya adalah para penggemar sastra, khususnya sastra klasik. BookTube yang membahas buku-buku dongeng seperti karya Roald Dahl dan Hans Christian Anderson pun cukup banyak. 
Indonesia pun tidak tertinggal, para content creator Indonesia ada beberapa yang spesifikasi kontennya termasuk BookTube. BookTube di Indonesia sebagian besar diciptakan oleh para pembaca buku dan juga penulis. Mereka itulah yang sejak awal rekam jejak di dunia mayanya selalu aktif dalam dunia buku dan literasi pada umumnya. Para BookTuber di Indonesia aktif menulis resensi dan mengkaji buku di blog. Kini, mereka mulai merambah untuk me-review buku secara audio dan visual.

Para BookTuber di Indonesia memiliki subscribers dalam kisaran 800 sampai 6.000 subscribers. Rata-rata tayangan BookTube ditonton oleh sekitar 600 sampai 9.000 viewers (penonton). Masih relatif sedikit untuk jumlah subscribers dan penonton dibanding tayangan prank atau gosip selebriti di YouTube. Ada tiga BookTuber yang memiliki jumlah subscribers terbanyak di Indonesia, yaitu Sophia Mega, Aya Sophia, dan Meggie Chen. Dunia BookTube di Indonesia sangat identik dengan ketiganya. BookTuber Indonesia pun menyajikan tayangan yang berisi ulasan buku, serba serbi penerbit, talk-show dengan penulis, penerjemah, atau editor, sampai mengulas pernak pernik buku. Semua hal tentang buku dibahas. Namun, tetap hal utama yang pasti ada adalah ulasan, kritik, dan resensi buku. Transformasi resensi buku yang biasa ditulis dan ada di media cetak menjadi sesuatu yang audio visual dan menampilkan tidak hanya bukunya tapi juga peresensinya lumrah terjadi. Media cetak saja sudah banyak yang mengembangkan sayap dalam wujud daring, tidak terkecuali konten-konten yang biasa ada di dalamnya. Resensi adalah salah satunya.

Perubahan-perubahan seperti ini merupakan proses yang terus menerus terjadi dalam masyarakat. Proses perubahan itu ada yang berjalan dengan sendirinya sehingga tidak terasa oleh masyarakat. itulah yang disebut evolusi (Ariyani \& Nurcahyono, 2014). Proses gerakan itu tujuannya ke arah masyarakat modern. Teori perubahan sosial dari Ogburn disebut teori fungsionalisme. Teori ini meyakini unsur kebudayaan baru yang memiliki fungsi bagi masyarakat akan lebih mudah diterima. Jika tidak memiliki fungsi sama sekali maka akan langsung ditolak. Adanya perubahan sosial disebabkan oleh beberapa hal. Untuk memetakan penyebab perusahaan sosial, maka dibagi dua antara faktor internal dan eksternal. Faktor internal yang menyebabkan terjadinya perubahan sosial adalah (1) bertambahnya atau berkurangnya penduduk; (2) adanya penemuan baru; (3) pertentangan (konflik) masyarakat; (4) terjadinya pemberontakan atau revolusi; dan (5) ideologi. Adapun faktor eksternal penyebab perubahan sosial adalah (1) lingkungan alam fisik yang ada di sekitar manusia; (2) peperangan; dan (3) pengaruh kebudayaan masyarakat lain (Waluya, 2017).

Fenomena BookTube ini dapat dikaji dengan kajian new media. Media baru atau new media dapat didefinisikan dalam empat kategori, yaitu media komunikasi interpersonal, media permainan interaktif, media pencarian informasi, dan media partisipatoris (McQuail, 2000). Ada perubahan pengalaman dalam menggunakan media baru dibanding menggunakan media lama, yaitu (1) kehadiran sosial, ketika merasa dapat terhubung dengan orang lain; (2) otonomi, ketika merasa memiliki kendali atas media yang dimiliki; (3) aktivitas timbal balik; (4) privasi; dan (5) kesenangan bermain, ketika merasa mendapatkan kesenangan ketika menggunakan media yang dimiliki (Ibrahim \& Akhmad, 2014).

Kehadiran sosial karena merasa dapat terhubung dengan orang lain dapat dilihat pada penggunaan media sosial yang semakin pesat, mulai dari Facebook, Twitter, Whatsapp, BBM, Google+, Tumblr, LinkedIn, Instagram, dan YouTube. Pemicu meledaknya media sosial adalah berkembangnya blog yang muncul di akhir tahun 1990-an (Ibrahim \& Iriantara, 2017). Media sosial mengubah bagaimana kita hidup (Ibrahim \& Iriantara, 2017). Sekarang, sudah tidak terasa aneh ketika undangan rapat, undangan pertemuan, bahkan undangan pernikahan dikirimkan dalam bentuk pesan atau foto di media sosial dan media chat. Kampanye politik atau gerakan sosial pun sekarang dapat menggunakan media sosial.

Berdasarkan penjelasan yang sudah dijabarkan, guna mengetahui, memahami, dan menjelaskan bagaimana para pembaca buku dan penonton tayangan BookTube memaknai kehadiran BookTube maka penelitian ini dilakukan. Berbicara mengenai perkembangan dunia digital dan kemampuan adaptasi untuk perubahan yang terjadi, ada beberapa penelitian terdahulu yang dilakukan sebelum penelitian yang penulis lakukan sekarang. Pertama, penelitian dengan judul "Konstruksi Makna Reputasi Digital Melalui Perspektif Penyiar Radio". Penelitian ini menggunakan metode kualitatif dengan pendekatan fenomenologis. Hasil dari penelitian ini menunjukkan makna reputasi digital bagi penyiar radio dibagi menjadi dua. Pertama makna yang berkenaan dengan diri penyiar radio sebagai individu (self-oriented). Kedua adalah makna reputasi digital yang berhubungan perusahaan, yaitu company oriented (Maudia et al., 2018).

Penelitian kedua berkaitan dengan konstruksi sosial terhadap makna perspektif alternatif dalam information sharing. Penelitian tersebut ditulis oleh Miranda dan Saunders yang berjudul "The Social of Construction of Meaning: An Alternative Perspective on Information Sharing". Dari penelitian ini diperoleh tiga hasil. Pertama, information sharing adalah persoalan interpretasi. Bukan sekadar menginformasikan, tetapi juga menginterpretasikan. Kedua, keberadaan sosial dari media komunikasi berefek pada interpretasi antarindividu. Ketiga, ketika face to face communication dan media elektronik harus dipilih, maka media elektronik adalah pilihan yang tepat sebagai medium (Miranda \& Saunders, 2016).

Selanjutnya, penelitian terdahulu mengenai BookTube pun pernah dilakukan dengan judul "The Boundaries of BookTube". Pada penelitian tersebut dijelaskan BookTube mampu mengaitkan jalinan para pembaca buku dengan pembaca buku lainnya dan penerbit. BookTube juga mampu mentransformasikan kegiatan atau aktivitas membaca yang soliter menjadi aktivitas yang bisa dinikmati langsung bersama-sama (Perkins, 2017). Ada juga riset terkait BookTube dengan judul "Negotiating Collaboration: BookTubers, The Publishing Industry, and YouTube's Ecosystem". Dengan 
konteks dunia perbukuan Spanyol, BookTube adalah hawa segar di dunia perbukuan Spanyol. Bahkan para pelaku penerbitan dan perbukuan mulai memperhitungkan BookTuber untuk berkolaborasi (Tomasena, 2019).

Penelitian ini memiliki irisan dengan penelitian terdahulu yang telah disebutkan, yaitu sama-sama membahas mengenai perkembangan teknologi, konstruksi makna, dan BookTube. Penelitian terdahulu terkait BookTube fokus pada pembahasan BookTube dan kaitannya dengan industri penerbitan dan perbukuan. Penelitian ini fokusnya pada pemaknaan pembaca buku dan penonton tayangan BookTube terhadap kehadiran BookTube sebagai pengganti resensi buku tertulis. Hal ini akan menambah khazanah riset terkait fenomena BookTube dari pemaknaan para pembaca buku terhadap BookTube itu sendiri karena pembaca bukulah yang menjadi target audiens dari BookTuber atau para pemilik BookTube.

\section{METODE PENELITIAN}

Penelitian ini menggunakan metode kualitatif dengan pendekatan fenomenologi. Penelitian ini mengumpulkan data dari sejumlah pembaca buku sekaligus penonton tayangan BookTube yang aktif dalam komunitas buku atau literasi melalui hasil wawancara dan observasi untuk selanjutnya dianalisis untuk memperoleh gambaran lengkap mengenai pemaknaan BookTube sebagai pengganti resensi buku tertulis. Selaras dengan tujuan utama penelitian kualitatif, yaitu untuk memahami fenomena gejala sosial berdasarkan gambaran lengkap fenomena yang sedang dikaji.

Pengumpulan data dilakukan melalui wawancara mendalam dan wawancara semi terstruktur tetapi memiliki satu fokus tertentu. Observasi pada penelitian ini adalah observasi pasif dan non-partisipatif, yaitu peneliti memperhatikan perkembangan BookTube dan sikap informan dalam memperoleh informasi mengenai sebuah buku. Selanjutnya adalah dokumentasi, yaitu penelusuran pustaka dan daring.

Analisis data yang dilakukan penelitian ini adalah analisis kualitatif, yaitu model analisis interaktif dan komparatif (Miles \& Huberman, 1994). Proses analisis dilakukan dengan tiga langkah. Pertama, reduksi data, yaitu menajamkan, menggolongkan, mengarahkan, dan mengorganisasikan data. Kedua, penyajian data, yaitu menyusun informasi yang telah terkumpul sehingga memungkinkan untuk ditarik kesimpulan. Ketiga, penarikan kesimpulan, yaitu menarik sebuah proposisi berdasarkan informasi yang muncul dari data, pola, penjelasan, dan alur yang ada pada tahap sebelumnya.

\section{HASIL DAN PEMBAHASAN}

Channel BookTube Indonesia yang sudah relatif dikenal adalah Aya Sophia, Sophia Mega, Kanvas Kata, Meggie Chen, Tarri Pewe, Dazling Books, dan Agie Eka. BookTuber Indonesia tergabung dalam komunitas BookTube id. BookTuber Indonesia pun sama halnya dengan BookTuber internasional yang menyajikan resensi dan ulasan buku yang mereka baca agar dapat memberikan informasi mengenai suatu buku dari hasil membaca mereka. Namun, tidak hanya itu, informasi lain pun disampaikan di channel BookTube mereka. Meski tidak hanya menayangkan resensi dan ulasan buku, informasi lain yang disampaikan itu tetap terkait dunia perbukuan, kepenulisan, dan literasi pada umumnya. Contohnya adalah informasi mengenai acara festival buku, diskusi dengan penulis, diskusi mengenai proses editing di penerbit, dan masih banyak lagi. Kekhasan dari resensi buku di BookTube adalah penyampaian tentang isi buku dibuat seringan dan sesantai mungkin meski buku yang sedang dibahas adalah buku dengan topik yang cukup serius. Bahkan, ada satu tayangan BookTube yang hanya menjelaskan sampul muka atau cover sebuah buku. Jadi, tidak hanya bicara konten buku, tetapi juga sampul muka dapat dibicarakan di BookTube.

Hasil penemuan dan pembahasan (diskusi) peneliti tuliskan sesuai dengan masalah yang diajukan dalam penelitian. Makna BookTube yang dimaknai informan adalah BookTube sebagai pelengkap dan BookTube sebagai pengganti resensi tertulis. Berdasarkan hasil reduksi dan pengelompokkan data hasil wawancara terhadap informan, dapat terlihat motif mengakses BookTube dan latar belakang mengakses BookTube.

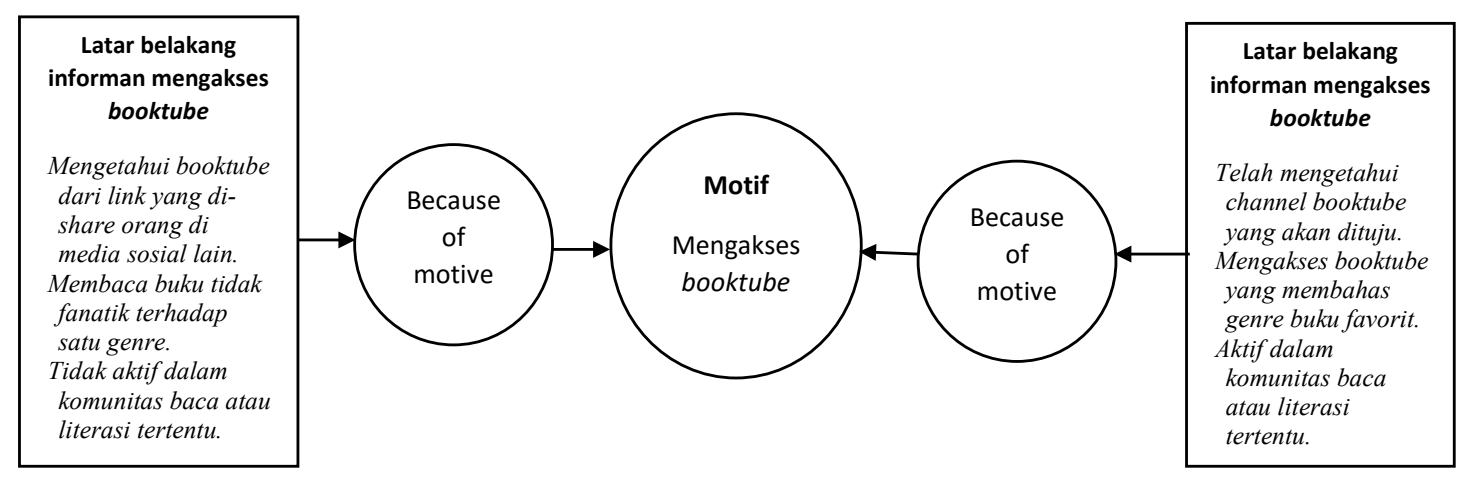

Gambar 1. Motif mengakses BookTube Sumber: Olahan Peneliti 
Dari hasil wawancara dan observasi diperoleh gambaran motif dari informan mengakses BookTube. Motif yang dimiliki ketika mengakses BookTube dapat dikategorikan menjadi dua dengan melihat gambaran di atas. Pertama, informan mengakses BookTube karena melihat tautan dari media sosial yang tertaut di channel BookTube seseorang. Dengan kata lain, informan ini berarti mengetahui dan mengakses BookTube secara tidak sengaja. Informan kategori ini pun bukanlah pegiat atau anggota komunitas literasi.

Sebagai produk teknologi baru, media sosial dapat meningkatkan kecepatan komunikasi. Fasilitas hyperlink atau tautan yang dapat dikoneksikan antara satu media dan media lainnya menunjang sebuah konten tersebar dengan cepat. Informan yang mengetahui BookTube karena melihat tautan di media sosial, meski pada awalnya tidak tahu akan menjadi tahu apabila mengklik tautan tersebut. Apalagi, jika tautan itu dipasang oleh seseorang yang dekat atau dianggap memiliki kredibilitas yang baik oleh informan sebagai pemberi informasi yang valid atau sesuai minat informan.

Adapun kategori kedua adalah informan yang telah mengetahui konsep BookTube. Bahkan, informan pada kategori ini sudah mengetahui dengan pasti channel yang akan diakses. Channel BookTube yang biasa diakses pasti sangat terkait dengan kesesuaian pada selera bacaan. Karena terbiasa aktif dalam kegiatan literasi, ketika mengakses BookTube bukan sekadar kegiatan random yang dilakukan. Informasi BookTube sendiri banyak diperoleh dan disebarluaskan melalui komunitas-komunitas literasi. Inilah yang disebut konsep playfulness dalam penggunaan media baru. Ada kesenangan yang dirasakan ketika menonton tayangan BookTube karena sesuai dengan minat informan dan memang khusus berisi konten yang menjadi favorit informan. Tentu saja, hal seperti ini tidak akan diperoleh dari media lama atau konvensional.

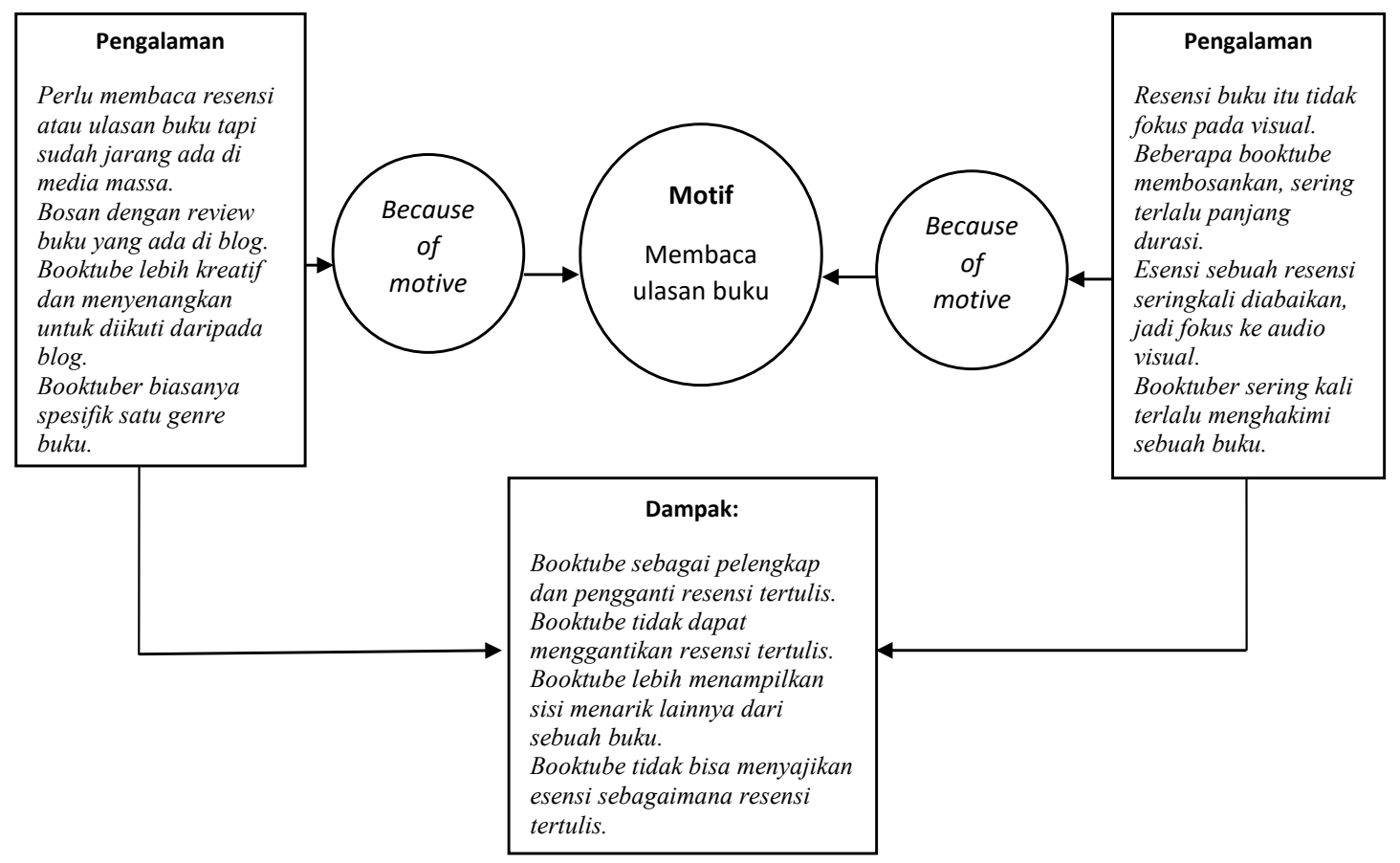

Gambar 2. Pengalaman dalam Mengakses BookTube

Informan pada kategori pertama mengakses BookTube dengan sengaja, bahkan sudah tahu channel siapa yang akan diakses. Informan kategori pertama ini merasa perlu mengetahui dulu ulasan buku sebelum membeli buku. Kebutuhan ini mulai tidak dapat dipenuhi dengan mencari di media massa. Ketika harus mencari random di blog pun, informan merasa bosan karena gaya ulasan buku para blogger buku seragam dan hampir sama. Akhirnya, diakses lah BookTube sebagai bentuk pemenuhan kebutuhan.

Manusia akan terus mencari jalan keluar untuk memenuhi kebutuhan yang sudah tidak dapat disediakan oleh zaman. Ketika zaman digital menjadi konteks kehidupan, maka manusia memiliki kemampuan untuk mengintegrasikan dirinya pada konteks zaman. Manusia memiliki kemampuan itu karena manusia adalah individu yang terintegrasi secara penuh (Maslow, 1957). Ketika mengenal BookTube disadari oleh informan bahwa BookTube jauh lebih kreatif dan mampu menampilkan bentuk ulasan atau resensi buku dengan menarik. Efek audio visual itulah yang membuat semakin menarik. Apalagi, jika informan adalah tipe audio visual. Salah satu informan juga menyampaikan bahwa keunggulan BookTube dibanding book blogger adalah fokus pada satu genre buku. Sebagian besar BookTuber memilih fokus pada satu genre buku yang memang jadi kesukaan mereka. Jadi, ketika orang mencari buku yang sesuai genre mereka, otomatis YouTube akan langsung menghadirkan channel mereka. Berbeda dengan para book blogger yang sebagian besar memiliki selera omnivora atau membaca berbagai genre buku. 
BookTube juga memunculkan perasaan berhubungan dengan orang lain atau social presence. Sebagai BookTuber, hasil membaca disampaikan secara lisan dan visual lalu diunggah di Youtube tentu memunculkan sebuah sensasi tersendiri. BookTuber akan merasa bahwa hasil membaca dapat didiskusikan dengan penonton BookTube-nya. Begitu pula penonton, adanya BookTube memunculkan perasaan terkoneksi langsung dengan BookTuber yang memiliki genre favorit yang sama dari sebuah buku.

Hal-hal yang disampaikan oleh informan kategori pertama berbeda dengan informan kategori kedua. Informan kategori kedua adalah yang mengakses BookTube secara tidak sengaja. Sebagian besar informan kategori kedua mengakui bahwa menemukan BookTube dari tautan lain di media sosial. Ketika akhirnya tahu pun, informan kategori dua merasa ada sesuatu yang kurang dari BookTube jika harus disebut pengganti resensi tertulis untuk mengulas dan menilai sebuah buku.

Pertama, informan kategori kedua teguh bahwa resensi itu harus tertulis, bukan ditampilkan secara visual. Sebagaimana konsep resensi yang sudah diketahui, resensi adalah suatu tulisan atau ulasan terhadap suatu karya, salah satunya adalah buku (Keraf, 1997). Akan tetapi, jika kita kaji secara etimologi, resensi itu tidak harus berbentuk tulisan. Resensi berasal dari bahasa Latin, revidere atau recensere yang bermakna 'melihat kembali, menimang' atau 'menilai' (Hidayah, 2016). Selama ulasan buku itu ada unsur penilaian dan pengamatan, baik lisan atau tulisan, maka dapat disebut resensi.

Selain karena informan kategori kedua belum menerima transformasi bentuk sebuah resensi ke dalam bentuk audio visual, informan pun merasa BookTube tidak menambah daya tarik apapun dari sebuah resensi. Informan merasa BookTube justru cenderung membosankan. Apalagi BookTube dari BookTuber memiliki durasi cukup lama. Biasanya para BookTuber menambah intro dulu sebagai pembuka video baru. Terkadang jika BookTuber tersebut menerima endorsement, maka durasi video pun bisa bertambah karena harus memberi spot waktu untuk menyampaikan produk atau jasa dari endorsement. Oleh karena itulah, informan kategori kedua ini sering merasa esensi dari sebuah resensi terabaikan jika disampaikan dalam BookTube. Tayangan video yang menyelipkan musik agar tidak bosan, sering mendistraksi untuk meraih esensi pembahasan buku. Visual yang ditampilkan pembahas pun membuat sulit berkonsentrasi penuh hanya pada pembahasan dan penilaian buku.

Istilah bahasa Inggris adalah review. Baik resensi ataupun review pada intinya sama, yakni mengulas buku. Tujuan resensi adalah memberikan pertimbangan kepada masyarakat apakah suatu karya atau buku dapat diterima atau tidak. Resensi sangat memperhatikan pertimbangan atau selera masyarakat. Oleh karena itu, tujuan sebuah resensi pun sangat bergantung pada sudut pandang siapa yang digunakan. Dari sudut pandang pembaca, resensi berfungsi untuk (1) mendapatkan informasi yang komprehensif tentang apa yang tampak dan terungkap dalam sebuah buku, (2) memberi pertimbangan kepada pembaca apakah layak untuk dibaca atau tidak, (3) mengajak pembaca memikirkan, merenungkan, dan mendiskusikan lebih jauh fenomena yang muncul pada sebuah buku, serta (4) mengetahui identitas buku yang patut dibaca (Rosidi, 2009). Dengan fungsi yang seharusnya dirasakan pembaca tersebut, resensi yang ditulis telah lama menunjukkan keberhasilan dalam menggapai tujuan dari resensi. Namun, ketika dipindahkan ke dalam tayangan BookTube, informan kategori kedua ini merasa BookTube belum dapat mencapai fungsi resensi bagi pembaca buku.

Hal lain yang dengan tegas disampaikan informan kategori kedua adalah penilaian yang terlalu menghakimi dari para BookTuber ketika membahas dan mengulas sebuah buku. Dalam resensi, penilaian dilakukan dengan menyampaikan dan menunjukkan keunggulan dan kelemahan dari sebuah buku. Penilaian harus disampaikan secara adil meski kita sangat menyukai atau sangat tidak menyukai buku yang sedang dibahas. Namun, menurut beberapa informan yang diwawancarai, BookTuber cenderung too judgy ketika menilai. Mereka tidak segan menggunakan kata sifat yang menunjukkan keburukan dari sebuah buku, seperti “duh covernya jelek banget”, dan lain-lain.

Jadi dalam hal ini, baik informan kategori pertama dan informan kategori kedua, mengonstruksi makna BookTube dari pengalaman masing-masing. Informan pertama menerima BookTube sebagai bentuk resensi baru yang jauh lebih menarik dan dekat dengan zaman. Akan tetapi, informan kategori pertama ini pun tidak menampik jika BookTube tidak sepenuhnya menggantikan resensi, melainkan melengkapi. Perubahan tentu tidak dapat ditampik. Ogburn mengatakan perubahan sosial adalah perubahan yang mencakup unsur-unsur kebudayaan, baik material maupun non material (Ogburn, 2018). Unsur-unsur kebudayaan material sangat dipengaruhi oleh unsur-unsur kebudayaan immaterial (Ogburn, 2018). Perubahan teknologi contohnya, pasti lebih cepat daripada perubahan budaya immaterial, seperti kepercayaan, norma, dan nilai-nilai. Perubahan teknologi sering memproduksi kejutan budaya yang akhirnya memunculkan pola-pola perilaku baru. Ketika resensi mengalami transformasi dalam bentuk digital, sehingga kini audiens lebih sering mengakses BookTube daripada membaca resensi, jelaslah ada perubahan sosial yang terjadi.

Perubahan yang menyebabkan resensi buku dapat berwujud audio visual melalui tayangan BookTube di YouTube adalah wujud nyata dari perubahan tersebut. Meskipun dalam bahasan mengenai BookTube, tidak terjadi kesenjangan yang lebar antara resensi buku dalam bentuk teks tertulis di media cetak dan resensi buku dalam tayangan BookTube. Kesenjangan berhasil diantisipasi dengan adanya adaptasi atau penyesuaian yang dilakukan terhadap YouTube itu sendiri jauh sebelum BookTube sebagai sebuah bentuk baru muncul. Akan tetapi, fenomena BookTube ini pun dapat dirasakan sebagai kejutan sosial. Ada beberapa sentuhan dalam resensi buku tertulis yang tidak dapat dipindahkan ke dalam tayangan 
BookTube. Unsur-unsur artifisial yang harus lebih banyak diutamakan dalam BookTube dapat menenggelamkan fungsi dan tujuan dari resensi itu sendiri.

Itulah yang menjadi salah satu alasan informan kategori kedua tetap bersiteguh bahwa BookTube tidak dapat menggantikan resensi dan fungsi dari resensi. Hal ini memperlihatkan adanya culture lag yang memang lazim muncul ketika sebuah perubahan atau transformasi terjadi. Adanya perubahan sosial tidak dipungkiri akan memunculkan culture lag. Adapun culture lag itu disebabkan ketika kebudayaan material mengalami perubahan yang sangat signifikan dari kebudayaan yang immaterial yang pada akhirnya menyebabkan sulitnya penyesuaian dari keduanya (Godin, 2017). Perubahan benda-benda budaya materi dalam hal ini adalah teknologi, berubah lebih cepat daripada perubahan dalam budaya non materi, seperti sistem dan struktur sosial. Teknologi yang berkembang dan berubah terus kita kejar dengan cara adat dan cara hidup diadaptasi untuk menyesuaikan dan memenuhi kebutuhan teknologi (Henslin, 2007). Padahal jika dilihat dari fungsi resensi untuk para penerbit, BookTube adalah cara yang paling tepat di dunia digital seperti sekarang. Resensi tidak hanya memiliki fungsi untuk penulis buku atau pembaca saja. Informasi yang disampaikan dalam sebuah resensi akan sangat berguna jika untuk penerbit. Misalnya, ketika penerbit mencari buku impor yang harus diterjemahkan, ketika melakukan riset pasti melihat animo dari pembaca melalui resensi. Baik itu resensi di blog, goodreads, ataupun BookTube.

Perbedaan pemaknaan untuk BookTube dari informan ini menyiratkan juga adanya sebuah perubahan yang telah terjadi. Perubahan yang muncul karena teknologi telah muncul. Dunia yang sekarang serba digital dan mengunggulkan Artificial Intelligence (AI) ini tidak bisa dihadapi dengan menutup diri dan bersiteguh dengan hal yang sudah mapan terjadi. Ketika perubahan harus terjadi, adaptasi perlu dipersiapkan. Teknologi yang berkembang dan berubah terus kita kejar dengan cara adat dan cara hidup diadaptasi untuk menyesuaikan dan memenuhi kebutuhan teknologi (Henslin, 2007).

Adanya BookTube yang secara fungsi seperti resensi buku juga memperlihatkan sebuah perubahan sosial yang disebabkan inovasi yang dilakukan kaum muda. Kaum muda menjadi produsen, konsumen, atau prosumen budaya sekaligus. Semangat menjadi produsen, konsumen, atau prosumen inilah yang memunculkan BookTube hingga sekarang memiliki komunitasnya sendiri, yaitu BookTube.id. Kaum muda mencoba menciptakan tren sendiri sekaligus menikmati tren tersebut. Media baru memang sangat lekat dengan karakteristik kaum muda yang seperti ini.

Perubahan yang perlu dipersiapkan dan disambut dengan matang ini juga merupakan salah satu cara pemenuhan kebutuhan manusia akan aktualisasi. Dunia yang serba digital tidak memungkinkan kita bertahan dengan cara yang usang atau mulai ditinggalkan. Buku-buku cetak mulai beralih ke digital. Penerbit mulai melirik pasar buku digital. Begitu pula ketika BookTube hadir dalam proses perubahan yang terjadi. Fungsi yang disebabkan oleh perubahan itulah yang seharusnya menjadi titik fokus dalam merespons perubahan. Jika berbicara fungsi, ketika dua media berfungsi sama, maka yang dipilih adalah yang paling menarik. BookTube yang hadir dengan kemasan baru sebuah resensi buku, tentu menjadi sebuah kebaruan dalam resensi.

Bukan berarti perubahan atau pergantian media akan menghapus secara permanen bentuk yang lama. Bentuk lama dapat bertransformasi untuk dapat bertahan hidup dengan mengubah fungsi atau membuat fungsi relevan dengan konteks zaman. Namun, tidak hanya fungsi baru, bentuk lama harus mampu mengubah persepsi khalayak. Resensi buku yang biasanya ditulis harus dapat mengubah persepsi khalayak tentang sebuah tulisan yang kering, tidak komunikatif, dan tidak memiliki kebaruan.

\section{KESIMPULAN}

Mulai absen dan hilangnya rubrik resensi dari media cetak konvensional direspons dengan book blogger pada awal tahun 2000-an. Kini, ketika YouTube menjadi situs web yang banyak digemari dan diakses, resensi bertransformasi dalam bentuk BookTube. Teknologi yang berubah sangat cepat menyebabkan respons pada BookTube pun berbeda. Meski dalam bentuk berbeda, BookTube tetap disepakati menyediakan paparan atau pembahasan sebuah buku disertai penilaian. Pemaknaan menjadi berbeda ketika BookTube dianggap sebagai pengganti atau pelengkap.

Jika sekarang BookTube masih dapat dianggap pelengkap karena masih ada resensi dalam bentuk tertulis, seiring waktu bisa saja BookTube benar-benar menjadi pengganti. Pemaknaan terhadap BookTube, baik sebagai pelengkap dan pengganti, beriringan dengan perubahan yang terjadi dalam konteks sosial. Ketika perkembangan teknologi komunikasi informasi semakin cepat, perubahan sosial akan terjadi, baik ikut tergesa-gesa, perlahan, ataupun tertatih. Siap tanggap dan terbuka adalah kunci penting dalam adaptasi menghadapi perkembangan ini.

\section{DAFTAR PUSTAKA}

[1] Ariyani, N. I., \& Nurcahyono. (2014). Digitalisasi Pasar Tradisional: Perspektif Teori Perubahan Sosial. Jurnal Analisa Sosiolog, 3(1), 1-12.

[2] Dogget, J. A. (2019). What is BookTube and Why Should You Be Watching (and Reading)?. https://www.huffpost. com/entry/what-is-BookTube_1_5cc06c21e4b01b6b3efb45ec 
[3] Duarte, F. (2019, September 9). Berapa banyak waktu yang dihabiskan rakyat Indonesia di media sosial? https:// www.bbc.com/indonesia/majalah-49630216

[4] Godin, B. (2017). Models of Innovation (The History of An Idea). The MIT Press.

[5] Henslin, J. M. (2007). Essentials of Sociology: A Down-to-Earth Approach. Penerbit Erlangga.

[6] Hidayah, N. (2016). Pembelajaran Bahasa Indonesia di Perguruan Tinggi. Penerbit Garudhawaca.

[7] Ibrahim, I. S., \& Akhmad, B. A. (2014). Komunikasi \& Komodifikasi. Yayasan Pustaka Obor Indonesia.

[8] Ibrahim, I. S., \& Iriantara, Y. (2017). Komunikasi yang Mengubah Dunia. Simbiosa Rekatama Media.

[9] Kartawijaya, B. (2020). Selamat Tinggal Pikiran Rakyat Minggu. https://budhiana.id/2020/03/15/selamat-tinggalpikiran-rakyat-minggu/

[10] Keraf, G. (1997). Komposisi. Nusa Indah.

[11] Maslow, A. . (1957). Motivation and Personality. Harper Publisher.

[12] Maudia, F., Hafiar, H., \& Sani, A. (2018). Konstruksi Makna Reputasi Digital melalui Perspektif Penyiar Radio. Profetik Jurnal Komunikasi, 11(1), 54-70.

[13] McQuail, D. (2000). McQuail's Mass Communication Theory (4th ed.). Sage.

[14] Miles, M. B., \& Huberman, A. M. (1994). Qualitative Data Analysis. Sage Publication, Inc.

[15] Miranda, S. M., \& Saunders, C. S. (2016). The Social of Construction of Meaning: An Alternative Perspective on Information Sharing. Information Systems Research, 14(1), 87-106. https://doi.org/http://dx.doi.org/10.1287/ isre.14.1.87.14765.

[16] Nailufar, N. N. (2019). Akankah TV Bernasib Sama dengan Koran dan Majalah? https://www.kompas.com/tren/ $\mathrm{read} / 2019 / 08 / 24 / 071300965 /$ akankah-tv-bernasib-sama-dengan-koran-dan-majalah?page=all

[17] Ogburn, W. F. (2018). Social Change with Respect to Culture and Original Nature. Creative Media Partners.

[18] Perkins, K. (2017). The Boundaries of BookTube. The Serial Librarian, 1-5.

[19] Romelteamedia. (2019). Daftar 29 Media Cetak yang Gulung Tikar Tergerus Media Online.

[20] Rosidi, I. (2009). Menulis Siapa Takut? Kanisius.

[21] Tomasena, J. M. (2019). Negotiating Collaboration: BookTubers, The Publishing Industry, and YouTube's Ecosystem. Social Media and Society, 1-12.

[22] Waluya, B. (2017). Sosiologi: Menyelami Fenomenas Sosial di Masyarakat. PT Setia Purna Inves. 